\title{
Principles of Hand Fracture Management
}

\author{
D.N. Haughton ${ }^{1}$, D. Jordan ${ }^{1}$, M. Malahias ${ }^{1}$, S. Hindocha ${ }^{*}, 1,2$ and W. Khan ${ }^{3}$ \\ ${ }^{I}$ Department of Plastic Surgery, Countess of Chester Hospital, Liverpool Road Chester, CH21UL. UK \\ ${ }^{2}$ Department of Plastic Surgery, Whiston Hospital, Warrington Road, L35 5DR, Liverpool, UK \\ ${ }^{3}$ University College London Institute of Orthopaedics and Musculoskeletal Sciences, Royal National Orthopaedic \\ Hospital, Stanmore, Middlesex, HA7 4LP, UK
}

\begin{abstract}
The hand is essential in humans for physical manipulation of their surrounding environment. Allowing the ability to grasp, and differentiated from other animals by an opposing thumb, the main functions include both fine and gross motor skills as well as being a key tool for sensing and understanding the immediate surroundings of their owner.

Hand fractures are the most common fractures presenting at both accident and emergency and within orthopaedic clinics. Appropriate evaluation at first presentation, as well as during their management, can significantly prevent both morbidity and disability to a patient. These decisions are dependant on a wide range of factors including age, hand dominance, occupation and co-morbidities.

A fracture is best described as a soft tissue injury with an associated bony injury. Despite this being the case, this paper intends to deal mainly with the bone injury and aims to discuss both the timing, as well as the methods available, of hand fracture management.
\end{abstract}

Keywords: Fracture, metacarpal, phalanges, injury, hand.

\section{HAND ANATOMY- A BRIEF REVIEW}

The hand consists of a main body known as the palm and five digits - a thumb and four fingers. Each hand is attached to the forearm at the wrist joint. There are twenty-seven bones within the hand, arranged into three distinct groups carpals, metacarpals and phalanges. The hand has a volar surface that includes the palm, and a dorsal surface that is commonly referred to as the "back" of the hand. The two lateral borders of the hand are commonly referred to according to their relation with the bones of the forearm, with the thumb forming the radial border and the little finger relating to the ulnar border. These terms are important when describing fractures and how they are displaced, subluxed or angulated.

The carpal bones form the base of the hand and the wrist joint, there are eight in total which are small and irregularly shaped. They are arranged into two separate rows, with the proximal row forming part of the wrist joint and the distal row articulating with the base of the metacarpal bones in the palm of the hand. Fractures to carpal bones are relatively uncommon and will not be discussed.

The main body of the hand is formed by the five metacarpal bones, and is commonly referred to as the palm. The metacarpal bones are numbered one to five, with one corresponding to the thumb and five the little finger. Each metacarpal has a base that articulates with the distal row of carpal bones. The body or shaft of each metacarpal is curved

*Address correspondence to this author at the Department of Plastic Surgery, Whiston Hospital, Warrington Road, Liverpool, L355DR, UK; Tel: 01244366265; Fax: 01244366265; E-mail: hindocha2001@yahoo.com and this gives the palm of the hand its characteristic cup shape. The shaft of each metacarpal widens at its distal end to form a neck and finally the metacarpal head. The dorsal surface of each metacarpal head is broad and flat, whilst the palmar surface has a central depression for the passage of the flexor tendons. The heads of the metacarpals are prominent structures and can easily be felt especially when the hand is made into a fist. They articulate with the proximal phalanx of each digit to form the metacarpal-phalangeal joints (MCPJ), which are more commonly known as the 'knuckles'. These are condyloid joints that allow flexion and extension of the digits, as well as a very small degree of abduction and adduction when the digits are extended.

The five digits of the hand begin at the MCPJ and are formed by the phalanges. There are fourteen phalangeal bones in the digits of the hand. The structure of each phalanx is similar to that of the metacarpal bones, each has a base, shaft, neck and head that is formed from two condyles.

The fingers are formed by three phalanges - proximal, middle and distal phalanx. These bones are arranged lengthways in relation to each other to give the long thin characteristic shape of the finger. The phalanges reduce in size from proximal to distal. There are two joints between the three phalanges in each finger, which are the proximal and distal interphalangeal joints (PIPJ, DIPJ). These joints are hinge joints that allow each finger to have two separate points of flexion and extension along its length. The joint capsule is reinforced on its volar aspect by the thickened ligament known as the volar plate that prevents hyperextension of the joint. The thumb is often considered a separate entity from the fingers and is formed from only two 
phalangeal bones referred to as proximal and distal, it therefore only contains one interphalangeal joint.

\section{METACARPAL FRACTURES AND ASSESSMENT OF THE HAND}

Fractures of the metacarpal are the most common of hand fractures accounting for up to $40 \%[1,2]$ and are usually the injury described as 'a broken hand' by the general public.

For discussion purposes fractures of the metacarpals are best described anatomically and the digits can be grouped together, although the fifth metacarpal is often expressed on its own as the 'boxer fracture' and accounts for a quarter of all metacarpal fractures [2]. Likewise, due to anatomical and functional variance the first metacarpal is generally classified as a separate entity, and will be discussed later in the paper on its own.

Management of fractures to the metacarpal bones of the hand is decided on both the clinical examination and radiological findings. The reasons behind this are that the hands long-term function is often dependant on the fractures angulation and rotation.

The key parts of the clinical examination is to assess the degree of rotational deformity, and whether there is any soft tissue compromise, including evidence of compound fractures with or without the involvement of a 'fight bite.' This term relates to the high incident of hand fractures secondary to punches and that a number of these involve a punch to an individual's mouth and thus an accidental 'bite' to the skin. Inability to extend at the metacarpophalangeal joint also correlates to increased need of operative fixation.

Rotation of the digit impacts greatly on functional grip, and can be a source of chronic pain [3]. lt is best assessed by asking the patient to make a fist. The digits of all 4 fingers should point towards the scaphoid tubercle, without overlapping with the MCPJ and PIPJ flexed (Fig. 1). Likewise the nail should appear parallel to the hand and neighbouring digits when looking end-on (Fig. 2). The digits should then tuck in as the DIPJ is flexed, although pain often restricts a degree of the flexion of all these joints. Comparison should be made to the other hand, but there is now a feeling that both digit overlap and nail alignment vary greatly within the population, making the clinical examination all the more difficul [4-6].

The radiological findings correlate to the angulation of the fracture, as well as metacarpal shortening. Metacarpal shortening appears to consequently affect interosseous function with a $10 \mathrm{~mm}$ loss of length corresponding to up to $55 \%$ muscle power loss [7].

Radiological views of the individual metacarpals are not possible. Posteroanterior and oblique views are mandatory. Ulnar digit injury lateral views should be optimally taken with 30-degrees pronation, and the radial digits with 30 degrees supination. However, angulation of the metacarpal bones is often best seen with a true lateral view. The Brewerton view can be useful if collateral ligament avulsion injury is suggested, and is taken with the MCPJ flexed at 65 degrees and the radiological view angled at a 15-degree angle ulnar to radial.

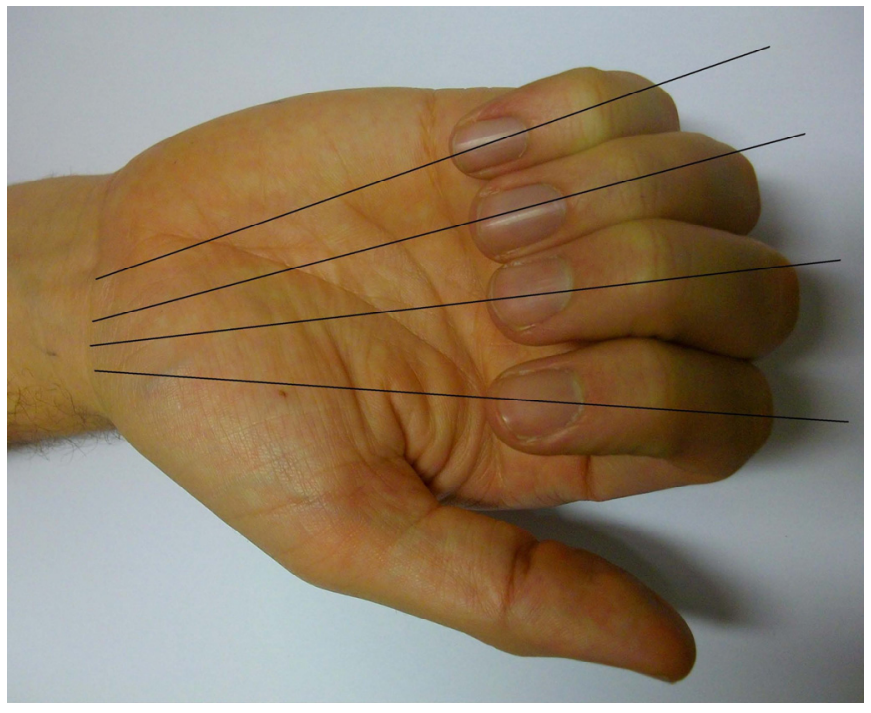

Fig. (1). The direction of the fingers when flexing to make a fist: pointing towards the area of the scaphoid tubercle. These lines are disrupted when the finger is rotated with the the rotated finger lying under neighbouring digits.
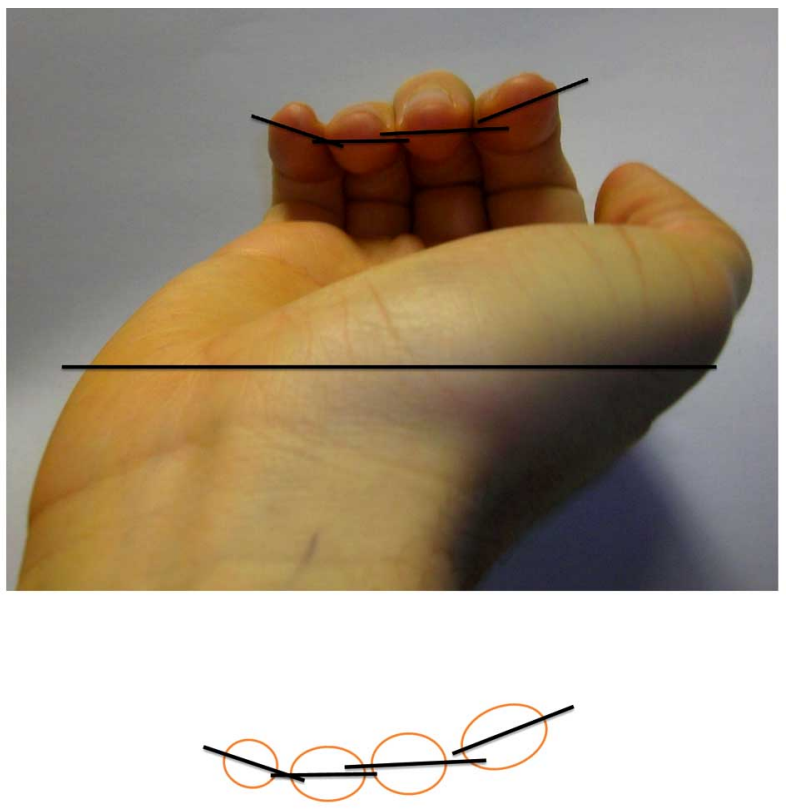

Fig. (2). Examination of rotation of the fractured digit. The fingers should be held with the MCPJ, PIPJ and DIPJ flexed and the angle of the nail should correspond to the plane of the palm. Some rotation may be normal for the patient (as in index and little finger in example).

\section{METACARPAL FRACTURES}

Fractures of the metacarpal bone either involve the proximal base, the shaft, neck, or the distal head. The neck and shaft are more commonly injured in contradiction to the first metacarpal where the base is most often involved. 
Fractures of the metacarpal head are by definition intraarticular, and are rarer than fractures involving the distal parts of the bone. The second metacarpal is the most common to be injured, and the cause is often as a result of a direct blow or crush injury. Fractures in this region are often comminuted, causing additional difficulty with their management. These injuries generally require open reduction and fixation although it is reported that metacarpal head fractures can be treated conservatively, with good long-term outcome if there is less than $25 \%$ joint involvement [8].

The neck of metacarpal is the most common site of fracture and is greatest in the two ulnar border digits, 4 and 5. The shaft of the metacarpal is also referred to as the body. The shaft can be fractured in 3 ways, oblique, transverse or spiral, and comminuted with the least protected fifth metacarpal at highest risk of injury [8]. Rotational deformity is greater in injuries to the shaft.

Both neck and shaft fractures are characteristically related to axial loading or direct trauma. Both typically angulate with a dorsal apex (Fig. 3). This angulation is often accepted due to the carpometacarpal (CMC) joint range of movement that can compensate for angles up to 10-15 degrees in the index and middle finger, and 20 degrees in the ring. The more proximal the fracture generally the greater the angulation, and the more noticeable any hand deformity such as clawing becomes. It has been reported that volar angles up to 70 degrees have been tolerated with conservative management and no long-term functional deficit [9].

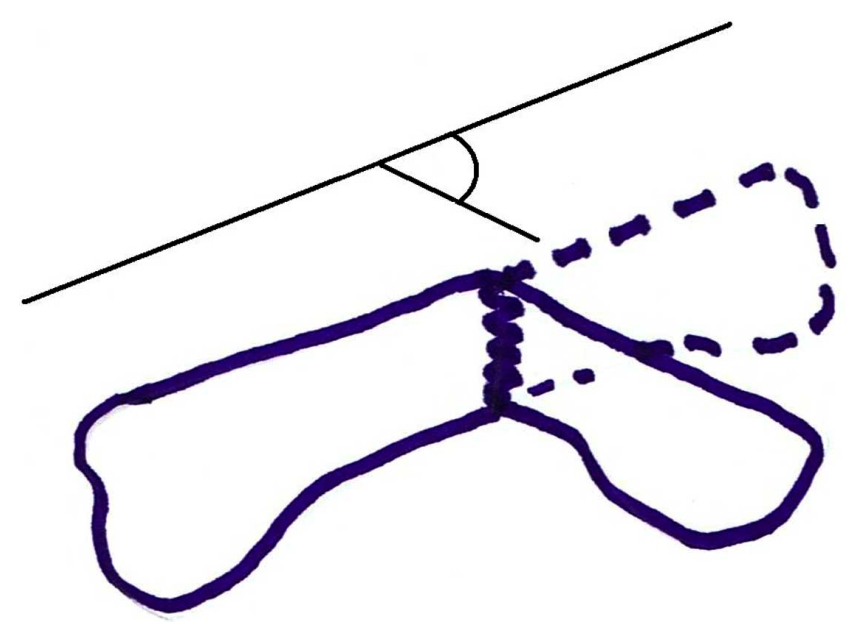

Fig. (3). Angulation measurement of metacarpal fracture.

The Boxer's fracture is a fracture involving the fifth metacarpal neck. There is no stabilisation along its ulnar aspect (the other digits have a neighbouring bone) and therefore fractures result in the metacarpal head being freed from any proximal attachments. This allows the head to rest in a greater volar angle and if left long term causes reduced metacarpal flexion due to collateral ligament shortening. Angulation of the head below 30-40 degrees is often acceptable in the fifth metacarpal, again thanks to CMC joint movements [10] and again angles up to 70 degrees have been successfully managed conservatively [11].

Fractures at the metacarpal base are the most stable of the metacarpal fractures due to both dorsal and palmar carpometacarpal, and the interosseous, ligaments. This stability is greatest in the second and third digits as there is some greater mobility allowed in the ulnar sided fourth and fifth digits [12].

They are generally classed as intra or extra-articular. Insertion of the flexor and extensor carpi muscles into the metacarpal bases (Radialis into the second and third metacarpal, and ulnaris into the fourth and fifth) can potentially aggravate any deformities. Intra-articular base of metacarpal fractures are uncommon but there may have a tendency of being both under-reported and diagnosed thanks to the stability of the surrounding structures [13].

\section{NON-SURGICAL MANAGEMENT OF METACAR- PAL FRACTURES}

Literature regarding management of any of the above fractures involving the metacarpals is vast although there appears to be no full consensus on particular pathways [14]. Non-operative techniques involve buddy strapping the injured digit to a neighbouring digit, with or without the application of varying degrees of splint including thermoplastic moulds or Plaster of Paris (POP) back slabs or cast. It is generally regarded that the 'buddy' or 'neighbour strap' reduces the risk of rotational deformity. Conventional teaching suggests splintage of the fracture with an aim of 20 degrees wrist extension, the metacarpophalangeal joint in 6070 degree flexion and interphalangeal joint extension [15].

This approach is described to reduce consequent ligament shortening and consequent reduction in initial and long-term hand function. However, several studies have suggested that both the degree of metacarpophalangeal extension or flexion as well as the amount of interphalangeal joint immobilisation does not have a significant impact on long term function, when looking at extra-articular fractures $[16,17]$.

One study reported good results with simple buddy strapping of the fractured fifth shaft to the ring finger as compared to a gutter POP, with no difference of function at twelve weeks as well as the former group having little to no hospital interaction after initial strapping and advice [18]. McMahon et al., found no significant difference between a compression bandage splint and POP managed stable shaft fractures, with a view for three-week immobilisation [19].

Metacarpal base fractures that are undisplaced and impacted can be conservatively managed [20].

Non-surgical management of the majority of shaft and neck fractures is generally accepted, as long as suitable reduction has occurred $[7,19]$. This is particularly noticeable in isolated third and fourth metacarpal fractures where the bones are well supported by the adjacent bones and strong intermetacarpal ligaments. Reduction of the angulated fracture can be attempted in the emergency setting, and is best done with the hand in 90 degree flexion at the metacarpophalangeal and proximal interphalangeal joints. Pressure is then applied on the dorsal aspect of the fracture with an attempt to 'push' the metacarpal head dorsally and flattening the shaft [21]. This technique can be attempted for closed fractures and although allows good reduction of the fracture, it is difficult to maintain this position as the hand cannot be splinted in this position due to long term clawing 
and flexion contracture formation, and the hand is placed in the above conventional position for POP application.

Again reports seem to support both conservative and operative management for metacarpal base fractures. Those with no or minimal displacement have been found to have satisfactory results in hand function, especially grip, with wrist immobilisation for 4 weeks [21]. Those with displacement can be treated with reduction of the fracture and $\mathrm{K}$ wire fixation, with subsequent POP for a similar time period [22-25]. One paper [26] where only base of fifth metacarpal fractures were treated, and all conservatively, appears to describe complications such as metacarpal shortening and joint problems which are not commented on in the other papers, and may suggest these complications do not occur with operative fixation.

\section{SURGICAL MANAGEMENT OF METACARPAL FRACTURES}

Indications for surgery include; open fractures, intraarticular fractures, angulation of the fracture greater than 30 degrees, rotational deformity greater than 10 degrees and gross $(>5 \mathrm{~mm})$ shortening of the metacarpal [27]. Likewise the irreducible or unstable fracture requires operative management, as does multiple digit involvement.

If the fracture is open, or a compound fracture, this requires formal debridement and irrigation, as well as appropriate antibiotic cover, and this can be done with reduction with or without fixation. Human bites, including the fight bite scenario, require intravenous antibiotics. Injuries involving extensive soft tissue loss, with or without bony injury require operative management too. Cosmetic and aesthetics of the hand may also precipitate surgical input.

Metacarpal fractures in general can be treated with Kirschner wire ( $\mathrm{K}$ wire), screws or intra-osseous wiring as well as the use of hand plates [28]. Each choice is more dependent on surgeon preference and skill rather than any particular benefit with the varying approaches [29]. Intraoperative radiography is generally required. Immobilisation for greater than two week is suggested with $\mathrm{K}$ wire fixation [15] and this method of fixation is generally believed to be the least invasive technique with maximum long-term function [30].

The fifth metacarpal often requires fixation after the base is fractured due to the deformity exaggerated by the pull of extensor, and to a lesser extent flexor, carpi ulnaris. K wires have long been the optimum management for these injuries. Intermedullary fixation of the fifth metacarpal neck fracture has been reported to give similar results to $\mathrm{K}$ wire fixation [31] although locking plates do not show any benefit and due to their cost do no justify their use [32]. With regard to how to pin this bone, intramedullary $\mathrm{K}$ wires have been shown to be more effective than a transverse approach but is more technically demanding [33].

In respect to the other metacarpals, shaft fractures can be stabilised with all the above techniques. In the case of transverse fractures, longitudinal $\mathrm{K}$ wires are best placed in a distal to proximal direction, whilst the use of cross pins should facilitate crossing of the pins near the fracture site. Transverse pins can be sited proximal (1 pin) and distal (2 pins) the fracture into the adjacent digits metacarpal.
Intramedullary and tension band wire fixation also give good long-term results although the former can be technically demanding and the latter involves an open route.

Oblique fractures of the shaft are amenable to longitudinal or transverse pinning as well as plate and screw fixation. Multiple lag screw fixation is a choice for long spiral fractures and again choice is more dependant on surgeon choice. Cadaveric studies showed comparable results, in terms of biomechanical strength, between bicortical interfragmentary screws and the more traditional lag screw [34] and is also shown to be a good alternative in the live patient [35].

One study showed good early mobilisation and long-term function with no complications using cerclage wire fixation for these injuries [36]. External fixation is also an alternative, but is more commonly used for severely comminuted injuries with loss of bone. Bone graft is a supplementary option in all of these injuries but is generally saved for bone loss related trauma.

Surgical fixation of the metacarpal fractures with plates does give good radiological reduction of fractures, but does involve complications including nerve and soft tissue injury as well as increased incidence of stiffness secondary to inflammatory reactions from the surgery [15]. Plate fixation of extra-articular fractures of the metacarpals has been found to have complications rates in up to $33 \%$ of patients including infection, complex regional pain syndrome and plate loosening [37]. These complications are counteracted by good immediate strength of the fracture fixation and so a quicker return to movement therapy [38].

Intramedullary nails have been shown to offer similar results to plate and screw fixation. The former requires a shorter operative time but was found to have a higher degree of secondary surgery for removal of the nail [39]. If the fracture requires fixation, with the development of microsurgery, mini screw fixation shows comparable results with that using $\mathrm{K}$ wire fixation. Bi-cortical self-tapping miniscrews for oblique fractures and uni- and bi-cortical screws for transverse fractures offer similar results [40].

Regarding the metacarpal head, if there is greater than 1$2 \mathrm{~mm}$ articular displacement or greater than $15 \%$ involvement, an open approach through a dorsal approach is required. Again $\mathrm{K}$ wires, cerclage wiring and screws are options with the key being whichever choice, including conservative, has to allow early and appropriate mobilisation.

In severely comminuted fractures the use of external fixation or conservative management is often favourable where $\mathrm{K}$ wires often fail. As a last resort, arthroplasty is an option.

A literature study by Bushnell et al., concluded that the second and third metacarpal base have been generally more successful with open reduction and internal fixation as opposed to conservative management. This is also seen in the rarer base of fourth metacarpal fracture too [41]. Multiple metacarpal fractures in the one hand with a closed injury are not common, and Souer and Mudugal [42]. Suggest plate fixation is a suitable option and is a safe, reliable and consistently reproducible method. 
As surgical techniques develop new methods are also being developed. For instance, bio-absorbable mini-plates for metacarpal fractures have been seen as a potential option with comparable results suggesting good stability in cadaveric studies [43]. There is increased concern regarding the absorbable implants with first designs involving foreign body reactions, which although improving implants appear to have reduced, may now just only be delayed, and require further study [44].

\section{THE FIRST METACARPAL}

The first metacarpal as stated varies in injury and management to the other metacarpal bones. It is the second most common metacarpal injured, accounting for just under $25 \%$ of all metacarpal fractures. Of these, four fifths relate to the base and due to the fact the thumb accounts for almost $40 \%$ of hand function these injuries take on major significance.

Thumb fractures are divided into four types, the first two involving the joint, whilst the last two are extra-articular.

Type I injuries are also known as Bennett's fracturedislocation, after its description by Dr Edward Bennett in 1882 [45] and involves a fracture dislocation of the base of the metacarpal. Characteristically the proximal part continues its attachment with the trapezium (the palmar beak) but the distal part is supinated and dislocated radially by the abductor pollicis muscles [46]. Type II injury, or Rolandos fracture, is a comminuted version of the Bennett's fracture. The proximal pieces form either a $\mathrm{T}$ or $\mathrm{Y}$ pattern, unless they are severely comminuted, and although rare all forms pose a complex management plan. Type III injuries are the most common of the four types, and are divided into transverse or the rarer oblique forms. Type IV will not be discussed in this paper and involves the proximal physis of paediatric patients.

\section{TYPE I INJURIES; BENNETTS FRACTURE DIS- LOCATION (FIG. 4)}

Type I fractures commonly occur after axial injuries [47], such as a punch, and is best reduced with longitudinal traction with abduction and extension of the thumb, followed by pronation of the digit to overcome Abductor pollicis brevis and longus. Although a thumb spica after closed reduction can be appropriate, greater than 1-3 $\mathrm{mm}$ of displacement or failure to maintain reduction warrants operative input [48]. The optionsbeing $\mathrm{K}$ wires, screws or a condylar plate [49-51].

No matter the choice of operative management, the degree of articular incongruity is associated with increased risk of future joint degeneration, where trapeziectomy is often later utilised [8,52-58] 2-6 weeks of immobilisation in a thumb spica is needed, even after operative fixation, followed by further management in a thermoplastic splint.

\section{TYPE II FRACTURES; COMMINUTED FRACTURE OF THE FIRST METACARPAL BASE (FIG. 4)}

Type II fractures were described in 1910, after a series of fractures were identified having three parts [59]. The Rolando fracture now describes most comminuted fractures of the base of the thumb metacarpal, and has a worse prognosis than its counterpart, the Bennett's fracture- dislocation. The majority require operative fixation, although the severely comminuted fracture is better treated in a thumb spica for up to four weeks before active exercises, due to the lack of bone to attach metalwork to. Saying this, external fixation is also a viable option [60,61], especially if conservative management has failed [62]. Large volar and dorsal fracture pieces allow surgical therapy, for which $\mathrm{K}$ wire, cortical lag screws and plates are available $[46,55,63]$. If only the former is used, dynamic traction can allows early mobilisation with good results [64].
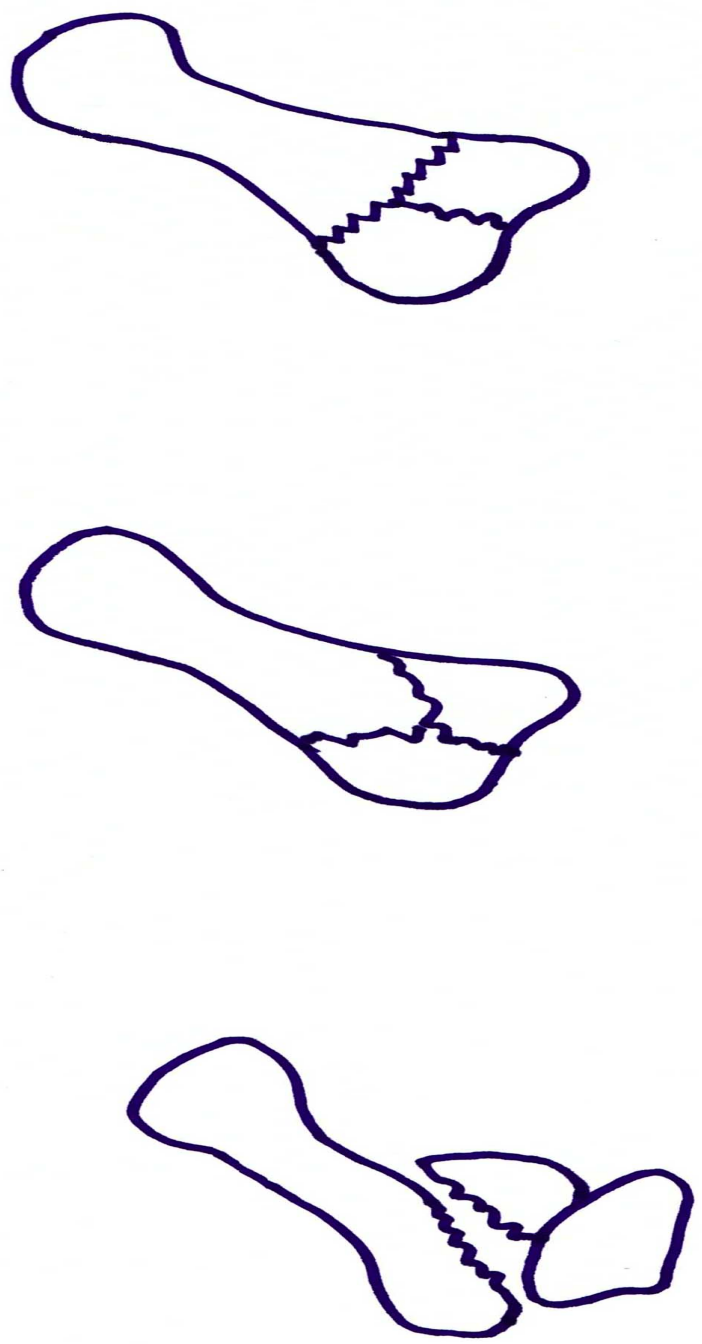

Fig. (4). Intra-articular, or Rolando, fracture (T type, top)(Y type, middle) and Bennett's fracture dislocation (bottom) of the first metacarpal.

\section{EXTRA-ARTICULAR FRACTURES OF THE FIRST METACARPAL}

The extra-articular fractures can generally be managed with conservative therapy [63], although screw and plate fixation are other options [65]. Intra-articular injury must be ruled out and computer tomography (CT) scanning may be required to fully diagnose this.

As with the other metacarpal shaft injuries, a degree of angulation is well tolerated, up to 30 degrees of what is commonly an adducted deformity. Deformity greater than this will usually require closed reduction and fixation with $\mathrm{K}$ 
wires, involving stabilisation through the trapezium carpal bone.

The main concern with shaft fractures of the first metacarpal is the potential loss of the first web space, caused by an adductor deformity, by both the flexor and extensor pollicis muscles, which consequently reduces both pinch and grip strength of the hand. Soft tissue management is key in long-term function and concerns with this area can be eased with external fixation or the use of $\mathrm{K}$ wires [60]. Likewise any open procedure involving the first metacarpal must not compromise the radial vessels.

\section{THE PHALANGES}

The fingers are particularly susceptible to trauma and injury, they can be easily trapped or crushed and have relatively little soft tissue to protect and support the underlying bones. For this reason fractures of the phalanges can often be open with varying degrees of soft tissue loss, and that inevitably complicates management.

Some phalangeal injuries may be difficult to spot and they are amongst the most commonly missed fractures. This can be due to inadequate or poorly taken radiographs, or simply the attending clinician not requesting an appropriate film [66]. One study recently showed that phalangeal fractures accounted for approximately $26 \%$ of all missed fractures [67].

Hand function and in particular use of the fingers is vital for most daily tasks and virtually every profession, it is important that patients with phalangeal fractures receive appropriate management to restore their normal function.

Management of phalangeal fractures is aimed at adequate anatomical reduction, maintaining fracture stability and early controlled mobilisation. A period of immobility for 2-3 weeks is generally accepted for most phalangeal fractures, anything longer than 3 weeks has been shown to increase long-term stiffness [68]. The difficulty comes in finding techniques that give good stability at the fracture site, but will also enable early mobilisations.

Historically these fractures were treated conservatively with closed reduction and immobilisation with splint or POP cast. The beginning of the $20^{\text {th }}$ century saw the introduction of percutaneous screws and $\mathrm{K}$ wires, and this has been a mainstay of treatment for most phalangeal fractures ever since [69]. The anatomy of the fingers makes percutaneous fixation methods technically quite straightforward, but more importantly effective. Certain fractures are however unsuitable for closed reduction and percutaneous fixation. Open and comminuted fractures, or those that are irreducible will often need open reduction and fixation with mini plating systems or external fixators. As a general rule of thumb stable phalangeal fractures can normally be treated successfully with conservative management, whilst unstable fractures require surgical fixation [70].

Phalangeal fractures can be broadly classified as being intra or extra-articular, simple or comminuted, that can be an open or closed injury. The vast majority of phalangeal fractures encountered are classified as extra-articular [71]. Intra-articular fractures include fractures through the base of the proximal phalanx involving the MCPJ, as well as any fracture of the PIPJ and DIPJ.
The proximal and middle phalanges share similar fractures patterns. Like the metacarpal bones they can be fractured at the base, shaft, neck and head. The proximal phalanx is the most commonly fractured of all the phalanges. The distal phalanx has its own unique fracture variations due to its size, position at the end of the finger and surrounding soft tissues.

\section{DISTAL PHALANX FRACTURES}

Injuries to the distal phalanx are most often crush-type injuries, which can frequently be "open" and there is usually an associated soft tissue and nail injury. The majority of fractures can be treated conservatively, and it is normally the initial repair of the surrounding soft tissues that is most important.

Tuft fractures affect the distal end of the phalanx, and are a result of a crush. They are typically comminuted fractures with very small fracture fragments, and therefore treatment is conservative. For a closed tuft fracture the initial treatment should be to decompress any associated subungual haematoma. Definitive treatment of the underlying fracture should be with a protective splint. Open tuft fractures should be thoroughly irrigated and the soft tissue repaired. As with any open fracture appropriate antibiotic treatment should be given. Although it is generally accepted that these fractures are best treated conservatively, it has been suggested that internal fixation can help prevent non-union [72].

Shaft fractures of the distal phalanx can be transverse or longitudinal and as a rule of thumb should be treated conservatively. However, if there is gross displacement of a transverse fracture it is possible to place a $\mathrm{K}$ wire into the fingertip, through the distal fragment and across the fracture site for stability.

Mallet fractures are extensor avulsion fractures of the distal phalanx involving the DIPJ, the finger is usually left flexed at the DIPJ due to the action of flexor digitorum profundus (FDP) on the distal fragment giving its characteristic appearance. There is loss of active extension at the DIPJ. Conservative management of mallet fractures involves continuous splinting of the DIPJ, which can be done in various ways over 6-8 weeks [73, 74]. Each particular splinting technique slightly differs however there is no difference in the overall final result [75].

Surgical treatment of mallet fractures is usually necessary if there is a large degree $(>30 \%)$ of articular surface involved, volar subluxation of the distal phalanx and for those cases were conservative management has failed [73]. Lucchina et al., compared the use of $\mathrm{K}$ wire versus open reduction internal fixation with interfragmentary miniscrews [76]. They found no statistically significant difference in functional outcome, but noted higher complication rates in those treated with open technique, although it did provide earlier mobilisation. The use of $\mathrm{K}$ wires is generally accepted to be more cost effective and reduces intra-operative time when compared to open reduction techniques, similar good results with $\mathrm{K}$ wire techniques have been shown in other studies $[77,78]$.

FDP avulsion fractures of the distal phalanx generally require surgical fixation. On examination there will be loss of the normal finger cascade, and the patient will be unable 
to flex at the DIPJ. These injuries can be complicated by retraction of the tendon and fracture fragment into the palm. The goal of treatment is to reinsert the tendon and fracture fragment. The traditional technique uses a "pull-out" suture or "button" technique. This involves passing sutures from the tendon, through the distal phalanx and fixed in place with a button on top of the fingernail. Newer techniques use bone anchor sutures to fix the avulsion directly onto the distal phalanx. Studies have shown bone suture anchors to have superior strength of repair [79]. There is little documented regarding complications arising from bone anchor sutures, however delayed protrusion has been reported [80].

\section{EXTRA-ARTICULAR PHALANGEAL FRACTURES}

Phalangeal neck fractures are uncommon in adults. They are by definition extra-articular fractures and relatively stable. Treatment is usually conservative however if there is gross displacement then surgery must be considered. AlQattan recently showed that neck fractures can be successfully treated with a combination of splinting, $\mathrm{K}$ wire fixation and early mobilisation. Undisplaced fractures were treated with splint for 3 weeks, whilst displaced fractures were fixed with percutaneous $\mathrm{K}$ wire after closed reduction. One patient required open reduction before $\mathrm{K}$ wire fixation, care was taken to ensure that both MCPJ and PIPJ were left free [81]. The most important factor for a good outcome in these fractures, as with the majority of phalangeal fractures, seems to be early mobilisation.

Phalangeal shaft fractures behave similar to metacarpal shaft fractures and demonstrate three main fracture patterns oblique, transverse and spiral. Following any necessary reduction, stable fractures can be treated conservatively with splints. Unstable shaft fractures need surgical fixation that can be either via closed or open technique using $\mathrm{K}$ wires and mini plating systems.

Conservative management of phalangeal shaft fractures with splints and traction has been reported with good outcomes in terms of range of movements and grip strength [71, 82].

Results have shown that $86 \%$ of patients treated conservatively with transverse, oblique and spiral fractures have full range of movement at 2-year follow-up [82]. Other papers have supported these good outcomes with conservative management for stable extra-articular fractures [71, 83].

When comparing functional outcome and malunion rates of oblique and spiral proximal phalangeal shaft fractures Horton et al., found no difference between treatment with percutaneous $\mathrm{K}$ wire and open reduction with lag screw fixation [84]. Other studies have also shown good results with closed reduction and $\mathrm{K}$ wire fixation [70]. Again it is important to allow free movements of the interphalangeal joints where possible. Stiffness of the DIPJ can be a problem in up to $50 \%$ of cases if the joint is initially immobilised through fixation [85]. As with metacarpal shaft fractures, bicortical screws can be used as an alternative to the traditional compression lag screw [35].

Open reduction and fixation with mini plates allow the finger to be mobilised straight away, however many feel that this technique can lead to higher risk of complications involved with greater dissection and injury to surround soft tissue. Plates are usually placed along the lateral border of the phalanx as to avoid the extensor mechanism. Interestingly despite the earlier mobilisation, one study showed that the most common long-term complication seen with plating systems is stiffness [86].

The use of cerclage wires for phalangeal shaft fractures is another possible ORIF technique. Al-Qattan examined 15 patients with oblique or spiral fractures of the proximal phalanx treated with cerclage wires, three patients had initial treatment with $\mathrm{K}$ wires that had failed. All of the fractures united, with twelve patients showing full return to normal function. There were no reported cases of wire extrusion however one patient did complain of a palpable wire and this was removed [87].

The use of external fixators in phalangeal fractures is usually reserved for open fractures with severe soft tissue injury/loss. The technique is relatively simple and avoids further trauma to the surrounding tissues. These patients require weekly check radiographs to monitor the fracture, and the device can be removed when sufficient healing is seen. Long-term ( $>$ 4years) follow up results show good return of function, and one study classed 20 out of 29 phalangeal fractures treated with an external fixator as good or excellent using the total active movement (TAM) scoring system [88]. Only minor complications were seen, the most common being pin loosening, and the majority could be easily removed as the fracture had already healed.

\section{INTRA-ARTICULAR PHALANGEAL FRACTURES}

Intra-articular fractures are notoriously difficult to treat. They have a higher incidence of long-term complications and can result in very poor function of the affected joint. As with all finger fractures, stiffness is a major problem in these fractures, particularly as early mobilisation can be difficult to achieve with conventional fixation methods. These fractures need prompt attention and any delay in surgery can affect the overall outcome. Unfortunately despite best efforts, many of these patients will develop severe degenerative changes and may require arthroplasty.

The PIPJ is the most common joint to be involved with intra-articular fractures of the fingers. The fracture can involve the head of the proximal phalanx and may be uni or bi-condylar, the base of the middle phalanx can also be involved at either its dorsal or volar lip.

In a study of 13 cadaveric hands, the fixation of unicondylar proximal phalangeal fractures was compared using compression screw, lag screw and $\mathrm{K}$ wires [89]. The results showed no difference in motion at the fracture site across the groups when stress was applied.

It is possible to achieve good range of movement with these fractures, one study showed 80-90 degree range of motion at 16 months follow-up at the PIPJ after treatment of proximal phalangeal head fracture using articular interfragmentary screws [90].

Minicondylar plates are also options for treating intraarticular fractures. They are however associated with relatively high complication rates and often become symptomatic [91]. They can produce good final outcome in terms of range of movement, although the best results are 
usually seen when they are used for fractures of the metacarpal head.

Intra-articular fractures of the PIPJ also commonly involve the base of the middle phalanx, which can either be the dorsal or palmar surface. Both variations are typically unstable fractures and require appropriate surgical fixation.

Grant et al., demonstrated that with adequate sized fracture fragments, the use of mini screw fixation can provide up to 115 degrees of movement 3 years after surgery [92]. An important finding from this study showed that any delay in surgery leads to reduced final range of motion and increased risk of further joint subluxations.

Dorsal fracture dislocations of the PIPJ can be treated with open or closed reduction and fixation. Ten patients treated with trans-articular $\mathrm{K}$ wires were followed up for 16 years and there were no reported severe degenerative joint changes seen [93].

These results differ greatly from the findings of a previous study were patients treated with either open reduction internal fixation or volar plate arthroplasty showed degenerative joint changes in $96 \%$ of cases [94]. They found that dislocation was the most common post-operative complication, and that this was evenly spread across the two groups.

External fixator devices are particularly useful for intraarticular phalangeal fractures. Li et al., showed overall TAM scores of good or excellent in 21 out of 26 patients treated with external fixator after 2 years follow-up [95]. The fixator was placed in a trans-articular manner, so that the centre of rotation of the fixator matches that of the joint it spans. This allows for early mobilisation. Initially the patients had weekly radiographs to monitor the position, and the device was typically removed after 4 weeks.

\section{THE POLLIX PHALANGES}

Very similarly to Metacarpal fractures, tuft fractures as well as simple undisplaced shaft fractures of the phalanges may be managed conservatively [96].

This can be achieved with a custom made thermoplastic splint or a thumb spica for two to three weeks [96, 97, 98]. The spica can be made by application of adhesive surgical tape in a criss-cross fashion (from proximal to distal) or with the use of plaster of Paris. The spica must not be applied too tightly, so as not to interfere with the circulation.

\section{SURGICAL MANAGEMENT}

Transverse fractures in the thumb are different to those in the fingers because of the strong pull of the flexor pollicis longus tendon. The traction on the fragments by that muscle causes displacement of these fractures, resulting in an unstable fracture. Manipulation, followed by fixation with the use of $\mathrm{K}$ wires, which cross the IP joint, is required for fracture stabilization. Longitudinal fractures are less common and often require open reduction and internal fixation with lag screws or cerclage wires [99]. With intraarticular fractures of the interphalangeal joint, that involve more than one third of the joint surface, operative treatment is indicated. If fragment size permits then $\mathrm{K}$ wire fixation, or open reduction with interosseous wiring or screw fixation, may be attempted [100].

\section{AVULSION FRACTURES OF THE ULNAR COLLATERAL LIGAMENT OF THE FIRST MCPJ}

If a small fragment of bone is associated with the avulsed ligament, then it should be resected. A larger fragment should be preserved and repaired, either with a trans-osseous stitch (using a non-absorbable suture) or with intra-osseous screw fixation [97, 98,101]. A thumb spica must then be applied to immobilise the metacarpophalangeal joint. The interphalangeal joint is to be left free. Mobilisation of that joint is advocated in the postoperative period, to prevent extensor tendon adhesions and stiffness. The cast is removed after four weeks [97, 98, 102, 103].

\section{HAND THERAPY}

Hand therapy is key whether the fracture is treated conservatively or operatively [104]. The hand bones typically unite within six weeks, although this is often delayed on radiological evidence. It appears to be universally accepted that mobilisation of the hand should occur before week 4; although no high level evidence has been conducted for this [105].

A study by Braakman et al., [106] showed a functional deficit with short-term application (one week) of immobilisation in a gutter splint when compared with neighbour strapping for neck of metacarpal fractures. The only difference in these techniques involves immobilisation of the metacarpal joint and resulted in extensor lag and reduced flexion which was significantly different at 4 weeks and still present in $8 \%$ of patients at 8 weeks post gutter splint compared to zero in the strapping group. However this therapy method is contradicted by other studies where splinting of the fracture helps to reduce pain and consequently improved range of motion compared to only buddy strapping $[107,108]$.

Wright appears to show that at three weeks of immobilisation related to shaft fractures can cause significant joint and soft tissue stiffness [109].

These studies all seem to suggest splintage to reduce the detrimental effect of pain, with early mobilisation gives quicker results in terms of function and return to work without detrimental affect to the fracture.

Surgical techniques allow some reduction in time before mobilisation. Open reduction has been shown to allow mobilisation from week 2 [110] whereas removal of $\mathrm{K}$ wires, at 4 weeks, precipitates range of movement exercises.

Malunion is the main concern in terms of complications with any management technique, and although overall results of metacarpal fractures are very good, no technique is failsafe.

\section{CONCLUSION}

Hand trauma is very common and associated loss of function can impact almost all activities. Multiple reports, case studies and literature searches have involved hand fractures. The conclusion with all of these, as is the case with this summary is that there are no large studies directing a conclusive management scheme in any of the hand fracture scenarios. Some hand fractures are amenable to conservative treatment, however unstable fractures usually require open or 
closed fixation and there are a variety of techniques available. The role of rehabilitation with early mobilisation cannot be underestimated.

\section{ACKNOWLEDGEMENTS}

None declared.

\section{CONFLICT OF INTEREST}

None declared.

\section{REFERENCES}

[1] Ashkenaze DM, Ruby LK. Metacarpal fractures and dislocations. Orthop Clin North Am 1992; 23: 19.

[2] Radiopaedia.org [homepage on internet] Metacarpal fractures. Available at: http://radiopaedia.org/articles/metacarpal-fractures (reviewed 20/10/2011)

[3] Bulcher U Gupta A, Ruf S. Corrective osteotomy for posttraumatic malunion of the phalanges in the hand. J Hand Surg $\mathrm{Br}$ 1996; 21: 33-42.

[4] Lahey PJ, Patel A, Kang KK, Patel MR, Choueka J. Assessing rotational deformity of the little finger Orthopaedics 2011; 34(7): 287.

[5] Tan V, Kinchelow T, Beredjiklian PK. Variation in digital rotation and alignment in normal subjects. J Hand Surg Am 2008; 33(6): 873-8. doi: 10.1016/j.jhsa.2008.02.006

[6] Bansal R, Craigen MA. Rotational alignment of the finger nails in a normal population. J Hand Surg Eur 2007; 32(1): 80-4. doi: 10.1016/j.jhsb.2006.09.011

[7] Meunier MJ, Hentzen E, Ryan M, Shin AY, Lieber RL. Predicted effects of metacarpal shortening on interosseous muscle function The Journal of Hand Surgery 2004; 29(4): pp. 689-93.

[8] Green DP, Pederson WC, Hotchkiss RN, Wolfe SW. Greens operative hand surgery. 5th ed. Churchill Livingstone, London, UK: Elsevier Health Sciences 2005.

[9] Ford DJ, Ali MS, Steel WM. Fractures of the fifth metacarpal neck: is reduction or immobilisation necessary? J Hand Surg 1989; 14B: $165-7$.

[10] Birndorf MS, Daley R, Greenwald DP. Metacarpal fracture angulation decreases flexor mechanical efficiency in human hands. Plast Reconstr Surg 1997; 99(4): 1079-83.

[11] Statius Muller MG, Poolman RW, van Hoogstraten MJ, Steller EP. Immediate mobilization gives good results in boxer's fractures with volar angulation up to 70 degrees: a prospective randomized trial comparing immediate mobilization with cast immobilization. Arch Orthop Trauma Surg 2003; 123(10): 534-7.

[12] El-Shennawy M, Nakamura K, Patterson RM, Viegas SF. Threedimensional kinematic analysis of the second through fifth carpometacarpal joints. J Hand Surg 2002; 26A: 1030-5.

[13] Crichlow TP, Hoskinson J. Avulsion fracture of the index metacarpal base: three case reports. J Hand Surg 1988; 13A: 212-4.

[14] Poolman RW, Goslings JC, Lee JB, Muller MS, Steller EP, Struijs PA. Conservative treatment for closed fifth (small finger) metacarpal neck fractures. Cochrane Database Syst Rev 2005; 20: CD003 210.

[15] McNemar TB, Howell JW, Chang E. Management of metacarpal fractures. J Hand Ther 2003; 16: 143-51.

[16] Tavassoli J, Ruland RT, Hogan CJ, Cannon DL. Three cast techniques for the treatment of extra-articular metacarpal fractures. Comparison of short-term outcomes and final fracture alignments. J Bone Jt Surg 2005; 87A: 2196-201.

[17] Hofmeister EP, Kim J, Shin AY. Comparison of 2 methods of immobilisation of fifth metacarpal neck fractures: a prospective randomized study. J Hand Surg 2008; 33A: 1362-8.

[18] Bansal R, Craigen MAC. Fifth metacarpal neck fractures: is follow-up required? J Hand Surg Eur 2007; 32E: 69-73.

[19] McMahon PJ, Woods DA, Burge PD. Initial treatment of closed metacarpal fractures. J Hand Surg 1994; 19B: 597-600.

[20] Lundeen JM, Shin AY. Clinical results of intraarticular fractures of the base of the fifth metacarpal treated by closed reduction and cast immobilization. J Hand Surg Br 2000 ; 25(3): 258-61.

[21] Jahss SA. Fractures of the metacarpals: a new method of reduction and immobilization. J Bone Joint Surg 1938; 20(1): 178-86.
[22] Bora FW, Didizian NH. The treatment of injuries to the carpometacarpaljoint of the little finger. J Bone Joint Surg 1974; 56: 1459-6318.

[23] Hsu JD, Curtis RM. Carpometacarpal dislocations on the ulnar side of the hand. J Bone Joint Surg 1970; 52: 927-30.

[24] Kjaer-Petersen K, Jurik AG, Petersen LK. Intra articular fractures at the base of the fifth metacarpal. J Hand Surg 1992; 17B: 144-7.

[25] Lundeen JM, Shin AY. Clinical results of intra articular fractures of the base of the fifth metacarpal treated by closed reduction and cast immobilisation. J Hand Surg 2000; 25B: 258-61.

[26] Petrie PWR, Lamb DW. Fracture-subluxation of the base of the fifth metacarpal. Hand 1974; 6: 82-6.

[27] Prokop A, Kulus S, Helling HJ, Burger C, Rehm KE. Are there guidelines for treatment of metacarpal fractures? Personal results and literature analysis of the last 12 years. Unfallchirurg 1999; 102(1): 50-8

[28] Büchler U, Fischer T. Use of a minicondylar plate for metacarpal and phalangeal periarticular injuries. Clin Orthop Relat Res 1987; 214: 53-8.

[29] Yan YM, Zhang WP, Liao Y, et al. [Analysis and prevention of the complications after treatment of metacarpal and phalangeal fractures with internal fixation].Zhongguo Gu Shang 2011; 24(3): 199-201.

[30] Kelsch G, Ulrich C. Intramedullary k-wire fixation of metacarpal fractures. Arch Orthop Trauma Surg 2004; 124(8): 523-6.

[31] Schädel-Höpfner M, Wild M, Windolf J, Linhart W. Antegrade intramedullary splinting or percutaneous retrograde crossed pinning for displaced neck fractures of the fifth metacarpal? Arch Orthop Trauma Surg (127) 6: 435-40.

[32] Facca S, Ramdhian R, Pelissier A, Diaconu M, Liverneaux P. Fifth metacarpal neck fracture fixation: Locking plate versus K-wire? Orthop Traumatol Surg Res 2010; 96(5): 506-12.

[33] Winter M, Balaguer T, Bessière C, Carles M, Lebreton E. Surgical treatment of the boxer's fracture: transverse pinning versus intramedullary pinning.. J Hand Surg Eur 2007; 32(6): 709-13.

[34] Liporace FA, Kinchelow T, Gupta S, Kubiak EN, McDonnell M. Minifragment screw fixation of oblique metacarpal fractures: a biomechanical analysis of screw types and techniques. Hand NY 2008; 3(4): 311-5.

[35] Roth JJ, Auerbach DM. Fixation of hand fractures with bicortical screws. J Hand Surg 2005; 30(1): 151-3.

[36] Al-Qattan MM, Al-Lazzam A. Long oblique/spiral mid-shaft metacarpal fractures of the fingers: treatment with cerclage wire fixation and immediate post-operative finger mobilisation in a wrist splint. J Hand Surg 2007; 32: 637-40.

[37] Fusetti C, Meyer H, Borisch N, Stern R, Santa DD, Papaloïzos M. Complications of plate fixation in metacarpal fractures. J Trauma 2002; 52 (3): 535-9.

[38] Lu WW, Furumachi K, Ip WY, Chow SP. Fixation for comminuted phalangeal fractures : a biomechanical study of five methods. J Hand Surg Br 1996; 2: 765-7.

[39] Ozer K, Gillani S, Williams A, Peterson SL, Morgan S Comparison of intramedullary nailing versus plate-screw fixation of extra-articular metacarpal fractures. J Hand Surg Am 2008; 33(10): 1724-31.

[40] Freeland AE, Orbay JL. Extraarticular hand fractures in adults: a review of new developments. Clin Orthop Relat Res 2006; 445: 133-45.

[41] Bushell BD, Draeger RW, Crosby CG, Bynum DK. Management of Intra-articular metacarpal base fractures of the second through fifth metacarpals. J Hand Surg 2008; 33A: 573-83.

[42] Souer JS, Mudugal CS. Plate fixation in closed ipsilateral multiple metacarpal fractures. J Hand Surg Eur 2008 ; 33(6): 740-4.

[43] Waris E, Ashammakhi N, Happonen $\mathrm{H}$, et al. Bioabsorbable miniplating versus metallic fixation for metacarpal fractures. Clin Orthop Relat Res 2003; 410: 310-319.

[44] Givissis PK, Stavridis SI, Papagelopoulos PJ, Antonarakos PD, Christodoulou AG. Delayed foreign-body reaction to absorbable implants in metacarpal fracture treatment. Clin Orthop Relat Res 2010; 468(12): 3377-83.

[45] Bennett EH. Fractures of the metacarpal bones. Dublin J Med Sci 1882; 73: 72-5

[46] Foster RJ, Hastings H 2nd. Treatment of Bennett, Rolando, and vertical intraarticular trapezial fractures. Clin Orthop Relat Res 1987; (214): 121-9. 
[47] Carlsen BT, Moran SL. Thumb trauma: bennett fractures, rolando fractures, and ulnar collateral ligament injuries. J Hand Surg Am 2009; 34(5): 945-52.

[48] Thurston AJ, Dempsey SM. Bennett fracture: a medium to longterm review. Aust N Z J Surg 1993; 63: 120-3.

[49] Wagner CJ. Method of treatment of Bennett fracture dislocation. Am J Surg 1950; 80: 230-1.

[50] Spangberg O, Thoren L. Bennett fracture: a method of treatment with oblique traction. J Bone Joint Surg 1963; 45B: 732-6.

[51] Lutz M, Sailer R, Zimmermann R, Gabi M, Ulmer H, Pechlaner S. Closed reduction transarticular kirschner wire fixation versus open reduction internal fixation in the treatment of Bennett fracture dislocation. J Hand Surg Br 2003; 28B:142-7.

[52] Gedda KO. Studies on Bennett's fracture; anatomy, roentgenology, and therapy. Acta Chir Scand Suppl 1954; 193: 1-114.

[53] Timmenga EJ, Blokhuis TJ, Maas M, Raaijmakers EL. Long-term evaluation of Bennett's fracture. A comparison between open and closed reduction. J Hand Surg Br 1994; 19(3): 373-7.

[54] Thurston AJ, Dempsey SM. Bennett's fracture: a medium to longterm review. Aust N Z J Surg 1993; 63(2): 120-3.

[55] Soyer AD. Fractures of the base of the first metacarpal: current treatment options. J Am Acad Orthop Surg 1999; 7(6): 403-12.

[56] Lutz M, Sailer R, Zimmermann R, Gabl M, Ulmer H, Pechlaner S. Closed reduction transarticular Kirschner wire fixation versus open reduction internal fixation in the treatment of Bennett's fracture dislocation. J Hand Surg Br 2003; 28(2): 142-7.

[57] Sawaizumi T, Nanno M, Nanbu A, Ito H. Percutaneous leverage pinning in the treatment of Bennett's fracture. J Orthop Sci 2005; 10(1): 27-31.

[58] Nagaoka M, Nagao S, Matsuzaki H. Trapeziometacarpal joint instability after Bennett's fracture-dislocation. J Orthop Sci 2005; 10(4): 374-7.

[59] Rolando S. Fracture of the base of the first metacarpal and a variation that has not yet been described 1910. Clin Orthop Relat Res Jun 1996; 327: 4-8.

[60] De Kesel R, Burny F, Schuind F. Mini external fixation for hand fractures and dislocations: the current state of the art. Hand Clin Aug 2006; 22(3): 307-15.

[61] Geissler WB. Cannulated percutaneous fixation of intra-articular hand fractures. Hand Clin 2006; 22(3): 297-305.

[62] Byrne AM, Kearns SR, Morris S, Kelly EP. "S" Quattro external fixation for complex intra-articular thumb fractures. J Orthop Surg Hong Kong 2008; 16(2): 170-4.

[63] Kahler DM. Fractures and dislocations of the base of the thumb. South Orthop Assoc 1995; 4(1): 69-76.

[64] Sarris I, Goitz RJ, Sotereanos DG. Dynamic traction and minimal internal fixation for thumb and digital pilon fractures. J Hand Surg 2004; 29(1): 39-43.

[65] Massart P, Bèzes H. Screw or mini-plate fixation in fractures of the first metacarpal. Experience with thirty-nine cases. Ann Chir Main 1982; 1(4): 293-300

[66] Tuncer S, Aksu N, Dilek H, Ozkan T, Hamzaoglu A. Fractures of the fingers missed or misdiagnosed on poorly positioned or poorly taken radiographs: a retrospective study. J Trauma 2011; 71(3): 649-55.

[67] Mounts J, Clingenpeel J, Mcguire E. Most frequently missed fractures in the emergency room. Clin Paedatr Phila 2011; 50(3): 183-6.

[68] Strickland JW, Steichen JB, Kleinman WB. Phalangeal fractures: factors influencing digital performance. Orthop Rev 1982; 11: 3950 .

[69] Bernstein ML, Chung KC. Hand fractures and their management: an international view. Injury 2006; 37: 1045-8.

[70] Singh J, Jain K, Mruthyunijaya, Ravishankar R. Outcome of closed proximal phalangeal fractures of the hand. Indian J Orthop 2011; 45(5): 432-8.

[71] Ozcelik D, Toplu G, Unveren T et al. Long-term objective results of proximal phalanx fracture treatment. Ulus Travma Acil Cerrahi Derg 2011; 17(3): 253-60.

[72] Hatanka W, Shibata S, Ochi H, Takahata N. Treatment of the distal phalangeal fractures in the hand. Hokkaido J Orthop Traumatol 2003; 44(2): 1-4.

[73] Anderson D. Mallet finger - management and patient compliance. Aust Fam Physician 2011; 40(1-2): 47-8.

[74] Tuttle HG, Olvey SG, Stern PJ. Tendon avulsion injuries of the distal phalanx. Clin Orthop Relat Re 2006 ; 445: 157-68.
[75] Handoll HH, Vaghela MV. Interventions for treating mallet finger injuries. Cochrane Database Syst Rev 2004; (3): CD004574.

[76] Lucchina S, Badia A, Dornean V, Fusetti C. Unstable mallet fractures: A comparison between three different techniques in a multicentre study. Chin J Traumatol 2010; 13(4): 195-200.

[77] Orhun H, Dursun M, Orhun E, Gurkan V, Altun G. Open reduction and $\mathrm{K}$ wire fixation of mallet finger injuries: mid-term results. Acta Orthop Traumatol Turc 2009; 43(5): 395-9.

[78] Lee SK, Kim KJ, Yang DS, Moon KH, Choy WS. Modified extension-block $\mathrm{K}$ wire fixation technique for the treatment of bony mallet finger. Orthopaedics 2010; 33(10): 728.

[79] Brustein M, Pellegrini J, Choueka J, et al. Bone suture anchors versus the pullout button for repair of distal profundus tendon injuries: a comparison of strength in human cadaveric hands. J Hand Surg Am 2001; 26(3): 489-96.

[80] Tiong WH, O'Sullivan ST. Extrusion of bone anchor suture following flexor digitorum profundus tendon avulsion injury repair. J Plast Reonstr Aesthet Surg 2011; 64(9): 1242-4.

[81] Al-Qattan MM. Phalangeal neck fractures of the proximal phalanx of the fingers in adults. Injury 2010; 41(10): 1084-9.

[82] Figl M, Weninger $\mathrm{P}$, Hofbauer $\mathrm{M}$, et al. Results of dynamic treatment of fractures of the proximal phalanx of the hand. J Trauma 2011; 70(4): 852-6.

[83] Koul AR, Patil RK, Philip V. Traction splints: effective nonsurgical way of managing proximal phalanx fractures. J Trauma 2009; 66(6): 1641-6.

[84] Horton TC, Hatton M, David TR. A prospective randomised controlled study of fixation of long oblique and spiral shaft fractures of the proximal phalanx: closed reduction and percutaneous $\mathrm{k}$ wiring versus open reduction and lag screw fixation. J Hand Surg Br 2003; 28: 5-9.

[85] Al-Qattan MM. K-wire fixation for extr-articular transverse/short oblique fractures of the shaft of the middle phalanx associated with extensor tendon injury. J Hand Surg 2008; 33(5): 561-5.

[86] Kurzen P, Fusetti C, Bonaccio M, Nagy L. Complications after plate fixation of phalangeal fractures. J Trauma 2006; 60: 841-3.

[87] Al-Qattan MM, Al-Zahrani K. Open reduction and cerclage wire fixation for long oblique/spiral fractures of the proximal phalanx of the fingers. J Hand Surg Eur 2008; 33(2): 170-3.

[88] Drenth DJ, Klasen HJ. External fixation for phalangeal and metacarpal fractures. J Bone Joint Surg Br 1998; 80(2): 227-30.

[89] Sirota MA, Higgins JP, Parks BG, Means KR. Stability of fracture fixation in condyle fractures in the proximal phalanges of the hand not a clinical study. J Hand Surg 2011; 36(8)(Suppl): 42.

[90] Tan JS, Foo AT, Chew WC, Teoh LC. Articularly placed interfragmentary screw fixation of difficult condylar fractures of the hand. J Hand Surg Am 2011; 36(4): 604-9.

[91] Ouellette EA, Freeland AE. Use of the minicondylar plate in metacarpal and phalangeal fractures. Clin Orthop Relat Res 1996; (327): $38-46$

[92] Grant I, Berger AC, Tham S. Internal fixation of unstable fracture dislocations of the proximal interphalangeal joint. J Hand Surg 2005; 30(5): 492-8.

[93] Newington DP, Davis TRC, Barton NJ. The treatment of dorsal fracture dislocation of the proximal interphalangeal joint by closed reduction and kirschner wire fixation: a 16 year follow-up. J Hand Surg Br 2001; 26(6): 537-40.

[94] Deitch MA, Kiefhaber TR, Comisar BR, Stem PJ. Dorsal fracture dislocations of the proximal interphalangeal joint: Surgical complications and long-term results. J Hand Surg Am 1999; 24(5): 914-23.

[95] Li W, Tian W, Tian G et al. Management of intra-articular fracture of the fingers via mini external fixator combined with limited internal fixation. Chin Med J 2009; 122(21): 2616-9

[96] Charles HT. Grabb and Smith's plastic surgery 2007; 6(81): 790802.

[97] Derkash RS, Matyas JR, Weaver JK, et al. Acute surgical repair of the skier's thumb. Clin Orthop 1987; 216: 29-33.

[98] Smith RJ. Post-traumatic instability of the metacarpophalangeal joint of the thumb. J Bone Joint Surg Am 1977; 59: 14-21.

[99] Hastings H. Unstable metacarpal and phalangeal fracture treatment with screws and plates. Clin Orthop 1987; 214 : 37-52.

[100] Rettig ME, Dassa G, Raskin KB. Volar plate arthroplasty of the distal interphalangeal joint. J Hand Surg Am 2001; 23(5): 940-4.

[101] Abrahamsson SO, Sollerman C, Lundborg G, Larsson J, Egund N. Diagnosis of displaced ulnar collateral ligament of the 
metacarpophalangeal joint of the thumb. J Hand Surg Am 1990; 15: 457-60.

[102] Gerber C, Senn E, Matter P. Skier's thumb: Surgical treatment of recent injuries to the ulnar collateral ligament of the thumb's metacarpophalangeal joint. Am J Sports Med 1981; 9: 171-7.

[103] Saetta JP, Phair IC, Quinton DN. Ulnar collateral ligament repair of the metacarpo-phalangeal joint of the thumb: A study comparing two meth- ods of repair. J Hand Surg Br 1992; 17: 160-3.

[104] Konradsen L, Nielsen PT, Albrecht-Beste E.Functional treatment of metacarpal fractures 100 randomized cases with or without fixation. Acta Orthop Scanz 1990; 61(6): 531-4.

[105] Feehan LM, Bassett K. Is there evidence for early mobilization following an extraarticular hand fracture? Journal of Hand Therapy 2004; 17(2): 300-8.
[106] Braakman M, Oderwald EE, Haentjens MH. Functional taping of fractures of the 5th metacarpal results in a quicker recovery. Injury 1998; 29: 5-9.

[107] Hansen PB, Hansen TB. The treatment of fractures of the ring and little metacarpal necks. A prospective randomised study of three different types of treatment. J Hand Surg 1998; 23B: 245-7.

[108] Harding IJ, Parry D, Barrington RL. The use of a moulded metacarpal brace versus neighbour strapping for fractures of the little finger metacarpal neck. J Hand Surg 2001; 26B: 261-3.

[109] Wright TA. Early mobilisation of fractures of the metacarpals and phalanges. Can J Surg 1968; 11: 491-8.

[110] La Stayo PC, Winters KM, Hardy M. Fracture healing: bonehealing, fracture management and current concepts related to the hand. J Hand Ther 2003; 16: 81-93.

(C) Haughton et al.; Licensee Bentham Open.

This is an open access article licensed under the terms of the Creative Commons Attribution Non-Commercial License (http://creativecommons.org/licenses/by-nc/3.0/) which permits unrestricted, non-commercial use, distribution and reproduction in any medium, provided the work is properly cited. 